\title{
Prognostic significance of AgNOR Proliferative Index in gallbladder carcinoma - A potential alternative to frozen section analysis
}

\author{
Sameer Gupta ${ }^{2}$, Sanjeev Misra ${ }^{1,2 *}$, Madhumati Goyal ${ }^{3}$, Vijay Kumar ${ }^{2}$, Arun Chaturvedi², Neeraj Kumar Arya ${ }^{3}$, Jaswant Jain ${ }^{2}$ and Naseem \\ Akhtar $^{2}$
}

${ }^{1}$ Director, A.I.I.M.S. (Jodhpur), Rajasthan, India

${ }^{2}$ Department of Surgical Oncology, King George's Medical University (K.G.M.U.), Lucknow, India

${ }^{3}$ Department of Pathology, King George's Medical University (K.G.M.U.), Lucknow, India

\begin{abstract}
Introduction: Number of Argyrophillic Nucleolar Organizer Regions (AgNORs) is a good indicator of cellular proliferation activity and is useful diagnostic tool to estimate the malignant potential of tumors.

Methods: Tissue sections from 40 cases of gall bladder disease, including 27 cases of gallbladder carcinoma and 13 cases of chronic cholecystitis, were studied for AgNORs count. The correlation of the AgNOR was carried out with various clinco-pathological parameters.

Results: Mean AgNOR counts in gallbladder cancer $(11.354 \pm 1.7866)$ were significantly higher than chronic cholecystitis $(2.0815 \pm 0.3731)$. Amongst patients with gallbladder carcinoma, well-differentiated $(9.5867 \pm 1.8928)$, moderately-differentiated $(11.1971 \pm 1.3181)$ and poorly-differentiated adenocarcinoma $(13.1829 \pm 0.9779)$ showed statistically significant difference in AgNOR counts. On inter stage comparison, study revealed progressive and statistically significant increase in AgNOR count from Tis to T4 stage. Mean AgNOR count for GBCs without metastasis was lower $(10.5186 \pm 1.6911)$ than metastatic GBC $(12.2538 \pm 1.4581)$, difference being statistically significant $(p=0.009)$.

Discussion and conclusions: Our results demonstrate that AgNOR parameters are useful indicators to evaluate malignant behavior of gallbladder carcinoma and its combination with conventional cytology may increase the diagnostic accuracy. AgNOR index can be used as a rapid, inexpensive and easily performed diagnostic tool to aid in early confirmation of a suspicious case of malignant gallbladder disease.
\end{abstract}

Keywords: Carcinoma gallbladder; Arygrophilic nucleolar region; Clinicopathological; Prognostic

\section{Introduction}

The Nucleolar Organizer Regions (NORs) were first described by Heitz (1931) and McClintock (1934) as weakly stained chromatin regions around which, at the end of telophase, nucleoli are reformed after their disappearance during the mitotic phase of the cell cycle. NORs, located on short arm of acrocentric chromrsomes (Chromosome number 13,14,15,21 and 22) contain ribosomal genes which encode for ribosomal RNA and play an important role in protein synthesis $[1,2]$. NORs are considered to be a marker of both DNA transcriptional activity and DNA transcriptional potential [3]. Associated with these regions are certain acidic and argyrophilic, non-histonic proteins called NOR-Associated Proteins (NORAPs). NORs can be demonstrated in tissue sections by staining their associated proteins with colloidal silver and these reaction products represent the Argyrophilic Nucleolar Organizer Regions (AgNORs) which appear as black dots of various sizes in the nucleolus and nucleus [4].

Number or size of AgNORs not only closely correlates with cellular proliferating activities, but also with cellular differentiation; thus it can be used for detecting malignancy and grading of the tumor [5]. Its role is well-established in the diagnosis of lymphoma, breast cancer, prostatic tumors, oral cavity tumors and other tumors but there have been very few studies evaluating the role of AgNOR count in biliarytract malignancies in general and carcinoma gallbladder in particular.

Carcinoma of the gall bladder is the most common malignant neoplasm of the biliary tract and fifth most common malignant neoplasm of the digestive tract. Incidence of gallbladder carcinoma shows marked gender (F: $\mathrm{M}=3: 1$ ) and geographical variations [6]. Highest incidence $(\sim 7 \cdot 5 / 100,000$ for men and 23/100,000 for women) is seen in Native American, South American and north Indian population.

Poor prognosis of this disease is due to the anatomical position of gallbladder and the high proportion of locally advanced tumours at the time of presentation. Despite the advances in imaging and diagnostic techniques, correct pre-operative diagnosis is made in $<10 \%$ of cases and curative resection is possible in only about a fourth of all cases. It has been a long felt need to identify diagnostic tools not only for early diagnosis of gallbladder cancer but also for evaluating the aggressiveness of the malignancy to guide further treatment.

The AgNOR is a cheap, simple, quick and reliable adjuvant to routine histopathological examination. NORs have been used to differentiate between benign, dysplastic (borderline) and malignant lesions in endometrium [7] and anal canal [8] and even to differentiate between various grades of dysplasias as in cervix uteri.

The aim of the present study is to calculate the AgNOR proliferative index in benign and malignant lesions of the gallbladder and to study their relationship with different clincopathological parameters. It also

${ }^{*}$ Corresponding author: Prof. Sanjeev Misra, Director, AlIMS (Jodhpur), Rajasthan, India, Tel: 05222324656; E-mail: misralko@gmail.com

Received November 14, 2013; Accepted December 10, 2013; Published December 18, 2013

Citation: Gupta S, Misra S, Goyal M, Kumar V, Chaturvedi A, et al. (2014) Prognostic significance of AgNOR Proliferative Index in gallbladder carcinoma - A potential alternative to frozen section analysis. J Liver 3: 143. doi:10.4172/21670889.1000143

Copyright: ( 2013 Gupta S, et al. This is an open-access article distributed under the terms of the Creative Commons Attribution License, which permits unrestricted use, distribution, and reproduction in any medium, provided the original author and source are credited. 
Citation: Gupta S, Misra S, Goyal M, Kumar V, Chaturvedi A, et al. (2014) Prognostic significance of AgNOR Proliferative Index in gallbladder carcinoma - A potential alternative to frozen section analysis. J Liver 3: 143. doi:10.4172/2167-0889.1000143

Page 2 of 6

aims to evaluate correlation between AgNOR counts and TNM stage and grades of differentiation of gallbladder carcinoma and explores its usefulness in assessing the aggressiveness and for prognostication of gallbladder malignancy.

\section{Material and Method}

\section{Patients}

The study was carried out in a tertiary care teaching hospital over a period of one year. A total of 40 histologically diagnosed cases of gall bladder disease were included in the study [neoplastic (27 cases of GBC) and non-neoplastic (13 cases of chronic cholecystitis) lesions of gall bladder].

For histology, after routine processing and paraffin embedding, several sections of 3-4 $\mu \mathrm{m}$ thickness were cut from each specimen. One section of each specimen was stained with haematoxylin and eosin and examined for histological diagnosis. In other sections, silver staining was done for AgNORs quantification.

\section{Laboratory procedures}

AgNORs staining method: One step colloidal silver staining method was used in this study, as described by Ploton et al. [9]:

i. Paraffin sections were cut at $3 \mu \mathrm{m}$ thickness and placed on serum coated slide and fixed at $37^{\circ} \mathrm{C}$ overnight.

ii. Sections were de waxed in Xylene and rehydrated in series of graded alcohol [in ethanol (100\%) for 2-5 minutes three times, then in ethanol (70\%) for 2-5 minutes once].

iii. Slides were washed in running tap water for 5 minutes and were then rinsed in deionized water for 2-3 minutes 2-3 times.

iv. AgNORs staining reagent was prepared in the dark by combining one volume of $2 \%$ gelatin solution in $1 \%$ formic acid with two volumes of $50 \%$ silver nitrate solution.

- Slides were covered with the solution and kept in dark with staining time of 20 minutes.

- Slides were washed 5 times in distilled water for 5 minutes each.

- Slides were dehydrated through series of graded alcohol.

- Slides were cleared in Xylene and mounted with Canada balsam.

AgNOR counting and interpretation: AgNORs appear as brown

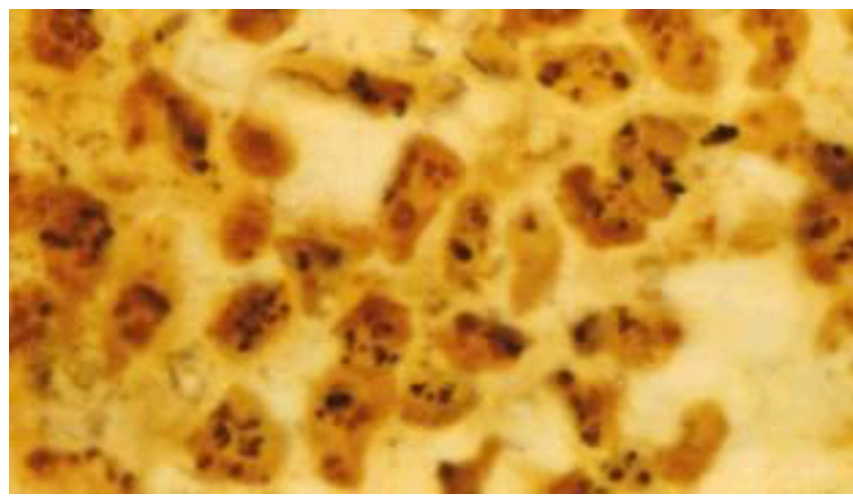

Figure 1: Case of Adenocarcinoma of gallbladder showing AgNOR dots in cluster form (AgNOR stain X 1000). or black dots of various sizes within a yellowish background of nucleus (Figure 1). AgNOR counting included direct count of each silver stained black colour dots in the nucleus and nucleolus by light microscope under oil immersion lens at 100x magnification by two blinded observers. In every section, 100 nuclei were examined in center of 10 fields. All the separate silver stained structures which could be clearly resolved were counted, whereas small dots overlapping each other were counted as one. The mean of the 100 nuclei were taken as the AgNOR index.

Statistical evaluation: The mean and standard deviation of all the parameters were assessed for each group. The inter-relationship of AgNOR expression with histology or clinical factors was analyzed using $\chi 2$ or Fisher's exact test. Significance of difference between these parameters was evaluated by student' $t$ ' test and data was compared between two groups under study. Apart from Students t test which was used for making comparison between two groups, comparison between more than two groups was made using ANOVA. The $\mathrm{p}$ values mentioned for multiple groups comparison in the tables is actually the one obtained after applying ANOVA with Games-Howell Post Hoc test. Corresponding p-values were calculated for the mean AgNORs and results were considered significant if a two-sided $\mathrm{P}$ value of less than 0.05 was obtained. Data entry and analysis were done using the Statistical Package for Social Sciences (SPSS) for Windows software (version 17.0; SPSS Inc, Chicago).

\section{Results and Observations}

In this study of 40 cases, 13 were non-neoplastic (chronic cholecystitis with or without cholelithiasis) lesions and 27 were histologically proven cases of carcinoma gallbladder. Patients in the non-neoplastic group underwent simple open/laparoscopic cholecystectomy and those with suspicion of gallbladder carcinoma underwent standard radical cholecystectomy with hepatoduodenal lymphnode dissection and segment IVb and V liver resection. 37.03\% $(n=10)$ of patients were found to have metastatic disease discovered during exploratory laparotomy and only biopsy from gallbladder mass/ lymph node was undertaken.

Patients in non-neoplastic group were younger [46.54 years (Range-33-58 years)] than neoplastic group [50.89 years (Range-35-68 years)] (Tables 1 and 2). Most common histological type of gallbladder malignancy was Adenocarcinoma ( $\mathrm{n}=20 ; 74.07 \%)$ followed by adenosquamous and mucinous type (Table 2). All 40 cases of gallbladder lesions were selected for AgNOR staining and were analyzed according to various clinical parameters viz. age, sex, histological grade, histological type, coexistant gallstones, TNM stage and distant metastasis.

\section{AgNOR counts in benign biliary diseases}

Mean AgNOR count in patients with chronic cholecystitis were 2.08 \pm 0.37 (Table 1) with no significant difference in patients of different age groups. Males had relatively higher mean AgNOR count $(2.22 \pm 0.61)$ than females $(2.04 \pm 0.31 ; \mathrm{p}$ value $=0.48)$. Patients with cholelithiasis had higher AgNOR count $(2.14 \pm 0.44)$ than patients without gallstones $(2.01 \pm 0.31 ; \mathrm{p}$ value $=0.565)$.

\section{AgNOR counts in malignant gallbladder lesions}

Mean AgNOR count in patients with GBC group [11.35 \pm 1.78 (Range $=6.24-14.32)]$ was significantly higher than chronic cholecystitis group $(2.08 \pm 0.37$ ); difference being statistically significant ( $\mathrm{p}=0.001$ ) There was no overlapping of values between two groups. In the subset 
Citation: Gupta S, Misra S, Goyal M, Kumar V, Chaturvedi A, et al. (2014) Prognostic significance of AgNOR Proliferative Index in gallbladder carcinoma - A potential alternative to frozen section analysis. J Liver 3: 143. doi:10.4172/2167-0889.1000143

Page 3 of 6

\begin{tabular}{|c|c|c|c|}
\hline & $N=13$ & Mean AgNOR \pm S.D & $\mathrm{p}$ Value \\
\hline $\begin{aligned} \text { Chronic } & \text { Cholecystitis } \\
- & \text { With Cholelithiasis } \\
- & \text { Without Cholelithiasis }\end{aligned}$ & $\begin{array}{c}10 \\
3\end{array}$ & $\begin{array}{l}2.14 \pm 0.44 \\
2.01 \pm 0.31\end{array}$ & 0.565 \\
\hline $\begin{array}{c}\text { Sex Distribution } \\
-\quad \text { Male } \\
-\quad \text { Female }\end{array}$ & $\begin{array}{c}3 \\
10\end{array}$ & $\begin{array}{l}2.22 \pm 0.61 \\
2.04 \pm 0.31\end{array}$ & 0.477 \\
\hline $\begin{array}{cc}\text { Age-wise Distribution } \\
-\quad 31-40 \text { years } \\
-\quad 41-50 \text { years } \\
=\quad 51-60 \text { years } \\
-\quad 61-70 \text { years }\end{array}$ & $\begin{array}{l}3 \\
7 \\
3 \\
0\end{array}$ & $\begin{array}{c}2.12 \pm 0.21 \\
2.07 \pm 0.44 \\
2.06 \pm 0.46 \\
0\end{array}$ & $p>0.05$ \\
\hline
\end{tabular}

Table 1: Clinicopathological details and Mean AgNOR counts of Non-neoplastic Group (Cholecystitis group).

\begin{tabular}{|c|c|c|c|}
\hline & $\mathrm{N}=\mathbf{2 7}$ & Mean AgNOR \pm S.D & p Value \\
\hline $\begin{array}{l}\text { Histological types of GBCs } \\
-\quad \text { Adenocarcinoma } \\
-\quad \text { Others } \\
\text { (Adenosquamous,Mucinous) }\end{array}$ & $\begin{array}{c}20 \\
7\end{array}$ & $\begin{array}{l}11.72 \pm 1.55 \\
10.32 \pm 2.13\end{array}$ & 0.074 \\
\hline $\begin{aligned} & \text { Sex } \text { Distribution } \\
&-\quad \text { Male } \\
& \text { - } \quad \text { Female }\end{aligned}$ & $\begin{array}{c}6 \\
21\end{array}$ & $\begin{array}{l}12.78 \pm 1.51 \\
10.95 \pm 1.67\end{array}$ & 0.024 \\
\hline $\begin{array}{c}\text { Age-wise Distribution } \\
-\quad 31-40 \text { years } \\
-\quad 41-50 \text { years } \\
-\quad 51-60 \text { years } \\
-\quad 61-70 \text { years }\end{array}$ & $\begin{array}{c}3 \\
12 \\
10 \\
2\end{array}$ & $\begin{array}{l}12.75 \pm 1.51 \\
10.73 \pm 1.90 \\
11.24 \pm 1.42 \\
13.57 \pm 0.21\end{array}$ & $p>0.05$ \\
\hline $\begin{aligned} \text { Gallbladder carcinoma } \\
\text { - } \quad \text { With Cholelithiasis } \\
\text { - } \quad \text { Without Cholelithiasis }\end{aligned}$ & $\begin{array}{l}16 \\
11\end{array}$ & $\begin{array}{l}11.03 \pm 1.77 \\
11.83 \pm 1.79\end{array}$ & 0.258 \\
\hline $\begin{aligned} \text { Histological Grades of differentiation } \\
\text { - } \quad \text { Well differentiated } \\
\text { - } \quad \text { Moderately differentiated } \\
\text { - } \quad \text { Poorly differentiated }\end{aligned}$ & $\begin{array}{c}6 \\
14 \\
7\end{array}$ & $\begin{array}{c}9.59 \pm 1.89 \\
11.19 \pm 1.14 \\
13.18 \pm 0.98\end{array}$ & $\begin{array}{l}\qquad p<0.05 \\
\text { On applying Post-hoc test, } \\
\text { Well diff. vs Mod. diff }-p=0.025 \\
\text { Well diff. vs Poorly diff. }-p=0.001 \\
\text { Mod.diff. vs Poorly diff. }-p=0.001\end{array}$ \\
\hline \begin{tabular}{|c|} 
TNM stage(Depth of invasion) \\
$-\quad$ Tis \\
$-\quad$ T1 \\
$-\quad$ T2 \\
$-\quad$ T3 \\
$-\quad$ T4 \\
\end{tabular} & $\begin{array}{l}1 \\
3 \\
8 \\
9 \\
6\end{array}$ & $\begin{array}{c}6.24 \\
10.03 \pm 0.85 \\
10.72 \pm 0.86 \\
11.56 \pm 1.24 \\
13.42 \pm 0.83\end{array}$ & $\begin{array}{c}\mathrm{p}<0.05 \\
\text { On applying Post-hoc test, } \\
\text { T1 vs T2- } p=0.266 \\
\text { T1 vs T3 }-p=0.079 \\
\text { T1 vs T4 }-p=0.001 \\
\text { T2 vs T3 }-p=0.131 \\
\text { T2 vs T4 }-p=0.002 \\
\text { T3 vs T4 }-p=0.007\end{array}$ \\
\hline $\begin{array}{c}\text { Gall bladder carcinoma } \\
\text { - } \quad \text { Without metastasis } \\
\text { - } \quad \text { With metastasis }\end{array}$ & $\begin{array}{l}17 \\
10\end{array}$ & $\begin{array}{l}10.52 \pm 1.69 \\
12.25 \pm 1.46\end{array}$ & 0.009 \\
\hline
\end{tabular}

Table 2: Clinicopathological details and Mean AgNOR counts of neoplastic (GBC) group.

of patients with GBC, highest mean AgNORs were recorded for 61-70 age group $(13.57 \pm 0.21)$ and lowest for $41-50$ age group $(10.73 \pm 1.9)$ (Table 2), though no statistically significant difference was observed. Males had relatively higher mean AgNOR count (12.78 \pm 1.51$)$ than females $(10.95 \pm 1.67)$ but in this subset of patients, the difference was statistically significant $(\mathrm{p}=0.024)$ (Table 2$)$. No statistically significant difference in AgNOR counts of GBC patients with or without associated cholelithiasis $(\mathrm{p}=0.258)$.

Amongst the various histological types of gallbladder carcinoma, mean AgNOR count in adenocarcinoma (11.72 \pm 1.55$)$ was only slightly higher than other histological subtypes $(10.32 \pm 2.13)$ (statistically insignificant; $p=0.074$ ) (Table 2). Progressive increase in AgNOR count was observed with decreasing grade of differentiation (Graph 2), with highest difference found between well-differentiated and poorly differentiated subtypes $(\mathrm{p}=0.001)$ and moderately differentiated and poorly differentiated subtypes $(\mathrm{p}=0.001)$ (Table 2$)$. The above mentioned findings suggest that AgNOR counts can act as a surrogate marker to differentiate between various histological grades of malignancies.
On interstage comparison of AgNOR counts in GBC patients, statistically significant difference was found in comparison between $\mathrm{T} 1$ vs T4 $(\mathrm{p}=0.001), \mathrm{T} 2$ vs $\mathrm{T} 4(\mathrm{p}=0.002)$ and $\mathrm{T} 3 \mathrm{vs} \mathrm{T} 4(\mathrm{p}=0.007)$ while nonsignificant difference found between $\mathrm{T} 1 \mathrm{vs} \mathrm{T} 2(\mathrm{p}=0.266)$ and $\mathrm{T} 1 \mathrm{vs} \mathrm{T} 3$ $(\mathrm{p}=0.079)$. These findings suggest that increase in mean AgNOR count is rapid in T4 stage which is significantly higher from lower stages, with higher AgNOR counts indicative of more advanced stage of malignancy (Graph 1).

Mean AgNOR count for GBCs without metastasis was lower $(10.52 \pm 1.69)$ than metastatic GBC (12.25 \pm 1.46$)$, difference being statistically significant $(\mathrm{p}=0.009)$ again indicating that AgNOR counts directly correlate with aggressiveness and advanced stage of the disease.

\section{Discussion}

Nucleolar Organizer Regions (NORs) are the tools, initially used by the cytogeneticist for the study of chromosomal disorders. AgNOR is a marker of cellular proliferation activity, similar to bromodeoxyuridine, DNA polymerase $\alpha, \mathrm{Ki}-67$ and Proliferating Cell Nuclear Antigen (PCNA) [10-13]. AgNOR count is a good indicator of cellular 


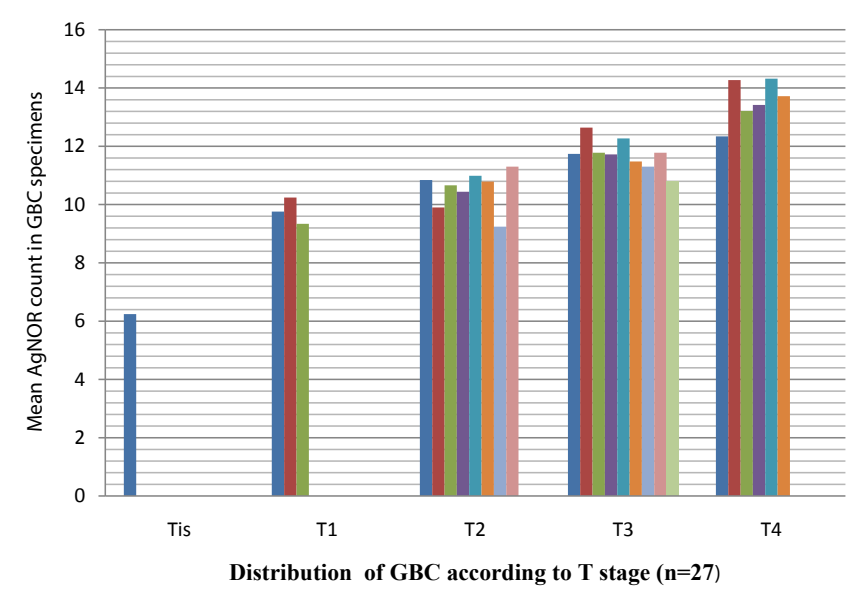

Graph 1: Distribution of mean AgNOR count in gallbladder cancer specimens according to the T-stage showing progressive increase from Tis to T4 stage.

proliferation activity and is useful as diagnostic tool to estimate the malignant potential of tumors. AgNOR counts are also shown to directly correlate with aggressiveness and advanced stage of the disease. Earlier studies have used NORs for the diagnosis of malignancies but gradually the attention has shifted toward its use in differentiating various grades of dysplasia and early malignancy from grade III dysplasia, thus aiding in the early diagnosis of malignancy.

Among the AgNOR proteins, major proteins are nucleolin and protein B23, estimated to account for $60-75 \%$ of the global staining [14]. The AgNOR silver staining technique is very simple, inexpensive and does not require special preservation, fixation of tissue or special instruments. It can be performed on formalin-fixed paraffin-embedded sections which is routine for the histopathologist. AgNOR staining method has been standardized for routine use in histopathology as recommended by International Committee on AgNOR Quanti-tation in 1995 so that comparable and reliable results from retrospective studies on formalin-fixed material can be obtained $[15,16]$. Therefore, at centers where more costly methods are not available for assessing tumor aggressiveness, study of the AgNOR count may become an important parameter to study the aggressiveness of the disease and may prove to be a good adjunct to presently available frozen section techniques and cytology.

In our tertiary care specialist oncology centre in Northern India region which reports one of the world's highest incidence rates for gallbladder carcinoma; our outpatient department receives upto 250-300 patients of carcinoma gallbladder per year. Though most of the patients present with advanced, inoperable and metastatic disease, significant percentage of these patients have incidentally detected gallbladder carcinoma, detected post-cholecystectomy (for cholelithiasis) on histopathological evaluation and by the time they are referred to specialist centres for definitive treatment, disease has progressed beyond stage of curative surgery. Use of AgNOR index as a rapid, inexpensive and easily performed diagnostic tool might aid in early confirmation of a suspicious case of malignant gallbladder disease and might help the surgeon in decision making as to the extent of surgery without waiting for the final histopathology report to direct the treatment and thus avoid delay in definitive treatment.

In the present study, we have tried to evaluate the usefulness of AgNOR index as more objective quantitative criteria in the clinicalpathological assessment of both benign and malignant gallbladder diseases. Correlation of the AgNOR index was carried out with various clinicopathological parameters as age, sex, TNM stage, histological type and grade of the tumor and metastatic disease. There are very limited studies, especially from Indian subcontinent, which reports one of the highest incidence of gallbladder cancer worldwide, evaluating the role of AgNOR index in gallbladder carcinoma as an adjunct to histopathological analysis $[17,18]$.

In the field of oral pathology, AgNORs have been used to differentiate oral squamous cell carcinoma from benign and reactive lesions and in detecting incipient cellular alterations [19]. AgNORs have been shown to be useful as a marker of tumor progression, to predict the response of tumor to treatment, and to detect residual viable tumor [20,21].

Nishizawa-Takano et al. reported that an increased number and increased size of AgNOR dots were significantly associated with lymph node metastasis, distant metastasis and shorter survival of patients who had undergone surgical resection of gallbladder cancers [22] They concluded that AgNOR number and AgNOR area, together with depth of neoplastic invasion and lymph node metastasis appear to be independent prognostic factors for survival in patients with gallbladder cancer [22].

In contrast to the study by Nishizawa-Takano et al. where there was no significant difference in AgNOR count amongst GBC patients in relation to sex, in our study mean AgNOR count in both GBC and chronic cholecystitis was higher in males as compared to females with statisitcally significant $(\mathrm{p}=0.024)$ difference seen in $\mathrm{GBC}$ subset in relation to sex. Mean AgNOR counts was higher in Adenocarcinoma compared to other histological subtypes but statistical analysis revealed no significant difference which is consistent with the findings as reported by Nishizawa-Takano et al. [22].

AgNOR counts have also been used to differentiate between various grades of malignancies. Correlations of AgNOR numbers with histological grades of tumors of central nervous system, lung carcinoma and salivary gland carcinomas have been documented [23-25]. One such study on oral squamous cell cancer revealed significant difference in mean AgNOR counts between different grades of malignany and also showed gradual increase in count from well-differentiated to poorly differentiated SCC [26]. Clinical correlation of AgNOR count with grades of differentiation in hepatobiliary malignancies is not as well studied with only a few small studies reported $[22,27,28]$.

According to study by Muscara et al., who compared the mean nuclear AgNOR area (NORA) and the AgNOR distribution score (NORDS) (i.e. the percentage of cells carrying nucleolar aggregates with more than 6 distinct silver dots) in 51 gallbladder surgical specimens including 32 primary carcinomas, 10 adenomas and 9 cases of chronic cholecystitis showed significant difference $(\mathrm{p}<0.001)$ between carcinomas and non-carcinomatous lesions. Both NORA and NORDS highly discriminated carcinomas with histopathological grade 4 versus cases with grade 1,2 or $3(\mathrm{p}<0.001)$. Both NORA and NORDS parameter permitted the discrimination of stage IV versus stage I carcinomas $(\mathrm{p}<0.001)[27]$

Our study substantiated the above findings, wherein poorly differentiated GBC showed a higher AgNOR count (13.18 \pm 0.98$)$ than well-differentiated $(9.59 \pm 1.89)$ or moderately differentiated $(11.19 \pm$ 1.14) subtypes of GBC (Graph 2); with statistically significant difference between the different histological types $(\mathrm{p}=0.001)$. Poorly differentiated $\mathrm{GBC}$ is more aggressive and highly proliferative compared to welldifferentiated GBC and hence the difference in the mean counts is on expected lines. In our study, evaluating the distribution of AgNOR 
Citation: Gupta S, Misra S, Goyal M, Kumar V, Chaturvedi A, et al. (2014) Prognostic significance of AgNOR Proliferative Index in gallbladder carcinoma - A potential alternative to frozen section analysis. J Liver 3: 143. doi:10.4172/2167-0889.1000143

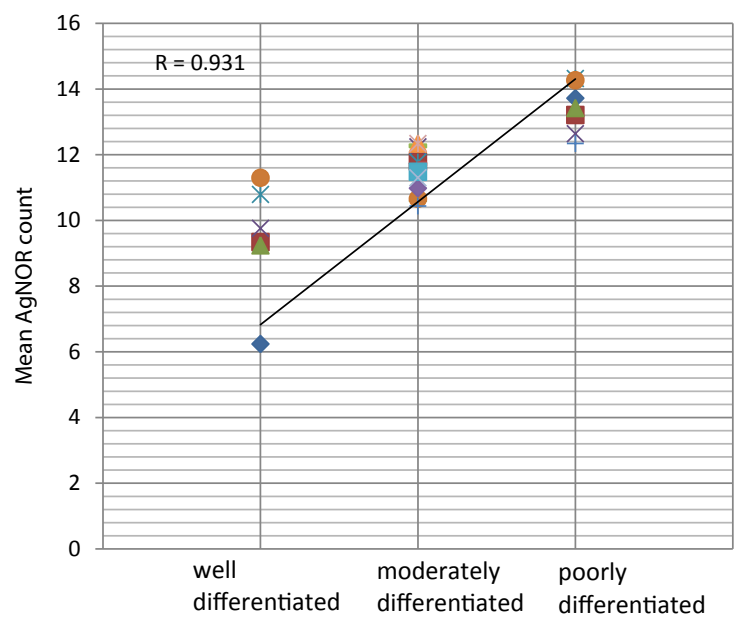

Distribution of GBC patients according to grade of differentiation

Graph 2: Correlation of mean AgNOR count with histological grade of differentiation of gallbladder cancer patients (examined by calculating the Pearson's correlation coefficient).

according to TNM stage, AgNOR count was lowest in Tis stage (6.24) while T4 stage had the highest mean AgNOR count (13.42 \pm 0.83$)$ with interim stages having progressively increasing AgNOR count from T1 to T3 (Graph 1). The interstage comparison revealed significant differences between $\mathrm{T} 1$ vs $\mathrm{T} 4(\mathrm{p}=0.001), \mathrm{T} 2$ vs $\mathrm{T} 4(\mathrm{p}=0.002)$ and $\mathrm{T} 3$ vs T4 ( $\mathrm{p}=0.007)$. Similarly, mean AgNOR count for GBCs without metastasis was lower $(10.52 \pm 1.69)$ than metastatic GBC (12.25 \pm 1.46$)$, difference being statistically significant $(\mathrm{p}=0.009)$.

Pollock studied the diagnostic value and cytophysiological correlation of NORs in the exocrine pancreas, in chronic pancreatitis and ductal adenocarcinoma, and concluded that AgNORs could differentiate between chronic pancreatitis and adenocarcinoma, and between different grades of adenocarcinoma [29]. Correlation was also found between number of extra-nucleolar dots and proliferation, as well as between number of intranucleolar dots and the protein synthetic activity of the epithelial cells of the small excretory ducts of the pancreas [30].

In their study, Crocker and McGovern recommended counting small AgNOR dots in both the nucleolus and nucleus in order to distinguish between benign and malignant cells. If AgNOR dots in nucleoli are not counted, difference in AgNOR counts is not significant, and there are many benign and malignant cells that show overlap of the number of dots in the nuclei [31]. Due to similar counting technique being used in the present study, AgNOR count in benign biliary diseases is significantly lower than in GBC subset.

In the study by Nanashima $\mathrm{A}$ et al, authors compared mean number of AgNOR dots per nucleus (MNA) of cells in bile specimens, obtained preoperatively with those of tissue specimens obtained during surgery [32]. The MNAs in malignant cells in bile smear $(9.6 \pm 3.8)$ and tissue sections $(9.2 \pm 3.5)$ were significantly higher than those in the corresponding cells in benign biliary diseases $(4.1 \pm 1.0$ and $2 \pm 0.8$ respectively; $\mathrm{p}$ vaue $<0.01$ ). The MNA of bile smear for both benign and malignant cells correlated significantly with that of tissue sections $(\mathrm{r}=0.915 ; \mathrm{p}$ value $<0.0001)$ [32].

Thus, our results demonstrate that AgNOR parameters are useful indicators to evaluate malignant behavior of gallbladder carcinoma and a combination of conventional cytology and AgNOR staining may increase the diagnostic accuracy. The technique of AgNOR staining is very easy, inexpensive compared with immunohistochemical or genetic analysis, and it takes only 15 min to complete.

\section{Conclusion}

AgNOR technique can aid in rapid diagnosis of malignancy in patients with clinical suspicion of gallbladder malignancy during surgery to determine the extent of operative procedure, which is especially relevant in areas such as North-Indian gangetic planes with one of the highest incidence of gallbladder carcinoma in the world. AgNOR proliferative index may be utilized as additional, more objective quantitative criteria in the clinical-pathological assessment of the outcome of gallbladder carcinomas. Furthermore, AgNOR count together with depth of neoplastic invasion and lymph node metastasis could prove to be independent prognostic factor for survival in patients with gallbladder carcinoma.

\section{References}

1. Kurvink K, Monica K, Porzucek MK (1990) Acrocentric interconnections and NOR variants in human lymphocytes. Cancer Genet Cytogenet 50: 207-226.

2. Crocker J, Nar P (1987) Nucleolar organizer regions in lymphomas. J Pathol 151: 111-118.

3. Dimova RN, Markov DV, Gajdardjieva KC, Dabeva MD, Hadjiolov AA (1982) Electron microscopic localization of silver staining NOR proteins in rat liver nucleoli upon D-galactosamine block of transcription. Eur J Cell Biol 28: 272277.

4. Crocker J, McGovern J (1988) Nucleolar organiser regions in normal, cirrhotic, and carcinomatous livers. J Clin Pathol 41: 1044-1048.

5. Derenzini M, Romagnoli T, Mingazzini P, Marinozzi $Y$ (1988) Interphasic nucleolar organizer region distribution as a diagnostic parameter to differentiate benign from malignant epithelial tumors of human intestine. Virchows Arch B Cell Patho 154: 334-340.

6. Misra S, Chaturvedi A, Misra NC, Sharma ID (2003) Carcinoma of the gallbladder. Lancet Oncol 4: 167-176.

7. Hansen A, Oestergard B (1990) AgNOR counts in intraepithelial neoplasias. J Clin Pathol 43: 518-519.

8. Ogunbiyi OA, Scholefield JH, Sharp F, Ginsberg R, Rogers K (1992) Nucleolar organizer regions in anal intra-epithelial neoplasoa and invasive anal squamous cell carcinoma. J Clin Pathol 45: 889-893.

9. Ploton D, Menager M, Jeannesson P, Himber G, Pigeon F, et al. (1986) Improvement in the staining and in the visualization of the argyrophilic proteins of the nucleolar organizer region at the optic level. Histochem J 18: 5-14.

10. Raza A, Ukar K, Preisler HD (1985) Double labeling and in vitro versus in vivo incorporation of bromodeoxyuridine in patients with acute nonlymphocytic leukemia. Cytometry 6: 633-640.

11. Mushika M, Miwa T, Suzuoki Y, Hayashi K, Masaki S, et al. (1988) Detection of proliferative cells in dysplasia, carcinoma in situ, and invasive carcinoma of the uterine cervix by monoclonal antibody against DNA polymerase alpha. Cancer 61: 1182-1186

12. Gerdes J, Schwab U, Lemke H, Stein H (1983) Production of a mouse monoclonal antibody reactive with human nuclear antigen associated with cell proliferation. Int J Cancer 31: 13-20.

13. Bravo R, Macdonald-Bravo $H$ (1985) Changes in the nuclear distribution of cyclin (PCNA) but not its synthesis depend on DNA replication. EMBO J 4: $655-661$.

14. Sirri V, Roussel $P$, Hernandez-Verdun D (2000) The AgNOR proteins: qualitative and quantitative changes during the cell cycle. Micron 31: 121-126.

15. Ofner D, Bankfalvi A, Riehemann K, Böcker W, Schmid KW (1994) A standardized AgNOR staining method for formalin fixed and paraffin embedded material. Pathologe 15: 226-230.

16. Ofner D, Schmid KW (1996) Standardized AgNOR analysis: its usefulness in surgical oncology. Histochem. Cell Biol 106: 193-196. 
Citation: Gupta S, Misra S, Goyal M, Kumar V, Chaturvedi A, et al. (2014) Prognostic significance of AgNOR Proliferative Index in gallbladder carcinoma - A potential alternative to frozen section analysis. J Liver 3: 143. doi:10.4172/2167-0889.1000143

Page 6 of 6

17. Gupta N, Kaur A, Pal S, Kahlon SK (2003) Study of nucleolar organizer regions (NORs) in lesions of gallbladder. Indian J Pathol Microbiol 46: 371-374.

18. Misra V, Misra SP, Dwivedi M, Gupta SC (1995) Role of AgNORs in diagnosis of early malignant lesions of gall bladder. Indian J Pathol Microbiol 38: 383-388.

19. Warnakulasuriya KA, Johnson NW (1993) Nucleolar organiser region (NOR) distribution as a diagnostic marker in oral keratosis, dysplasia and squamous cell carcinoma. J Oral Pathol Med 22: 77-81.

20. Pillai KR, Sujathan K, Madhavan J, Abraham EK (2005) Significance of silverstained nucleolar organizer regions in early diagnosis and prognosis of oral squamous cell carcinoma: A multivariate analysis. In Vivo 19: 807-812.

21. Nakamura M, Sano K, Kitagawa Y, Ogasawara T, Nishizawa S, et al. (2004) Diagnostic significance of FDG-PET and argyrophilic nucleolar organizer regions (AgNORs) in oral squamous cell carcinoma. Oral Oncol 40: 190-198.

22. Nishizawa-Takano JE, Ayabe H, Hatano K, Yamaguchi H, Tagawa Y (1996) Gallbladder cancer. A comparative study among clinicopathologic features, AgNORs and DNA content analysis. Dig Dis Sci 41: 840-847.

23. Korkolopoulou P, Christodoulou P, Papanikolaou A, Thomas-Tsagli E (1993) Proliferating cell nuclear antigen and nucleolar organizer regions in CNS tumors: Correlation with histological type and tumor grade. Am J Surg Pathol 17: $912-919$

24. Nanomura A, Mizukami Y, Oda M, Shimizu J, Watanabe $Y$, et al. (1993) Demonstration of nucleolar organizer regions in lung carcinoma by silver staining. Surg Today 23: 486-490.

25. Alaeddini M, Khalili M, Tirgary F, Etemad-Moghadam S (2008) Argyrophilic proteins of nucleolar organizer regions (AgNORs) in salivary gland mucoepidermoid carcinoma and its relation to histological grade. Oral Surg Oral Med Oral Pathol Oral Radiol Endod 105(6): 758-762.

26. Chatterjee R, Mukhopadhyay D, Chakraborty RN, Mitra BR (1997) Evaluation of argyrophilic nucleolar organizer regions (AgNORs) in oral carcinomas in relation to human papillomavirus infection and cytokinetics. J Oral Pathol Med 26: 310-314

27. Muscara M, Giuffre G, Rossiello R, Sarnelli R, Barresi G, et al. (1996) Gallbladder carcinoma: a video image analysis of AgNOR distribution and its relation to tumour stage and grade. Pathol Res Pract 192: 407-413.

28. Suzuki T, Takano Y, Kida Y, Okudaira M (1993) Silver-binding argyrophilic nucleolar organizer regions (AgNOR) in gall-bladder cancer: correlations with malignant grading and prognosis. Acta Pathol Jpn 43: 36-43.

29. Pollok A (1997) Nucleolar organizer regions in exocrine pancreas in chronic pancreatitis and ductal adenocarcinoma-Diagnostic value and cytophysiologic correlate. Gen Diagn Pathol 142: 199-209.

30. Khanna AK, Yadav SK, Dixit VK, Kumar M (2005) AgNOR Count and Subjective AgNOR Pattern Assessment (SAPA) Score in Carcinoma of the Pancreatic Head Including Periampullary Tumors. J Pancreas 6: 575-580.

31. Crocker J, McGovern J (1988) Nucleolar organiser regions in normal, cirrhotic and carcinomatous livers. J Clin Pathol 41: 1044-1048.

32. Nanashima A, Yamaguchi H, Nishizawa-Takano JE, Hatano K, Shibasaki S et al. (2002) Application of argyrophilic nucleolar organizer region (AgNOR) staining for cytology of biliary tract carcinomas. J Hepatobiliary Pancreat Surg 9: 485-489. 